\title{
Nasal nitric oxide concentration in paranasal sinus inflammatory diseases
}

\author{
J-F. Arnal*, P. Flores**, J. Rami*, M. Murris-Espin ${ }^{+}, F^{+}$Bremont $^{+}$, M. Pasto I Aguilla*, E. Serrano**, \\ A. Didier
}

Nasal nitric oxide concentration in paranasal sinus inflammatory diseases. J-F. Arnal, P. Flores, J. Rami, M. Murris-Espin, F. Bremont, M. Pasto I Aguilla, E. Serrano, A. Didier. (C) ERS Journals Ltd 1999.

ABSTRACT: In normal upper airways, nitric oxide is generated by the paranasal sinus epithelium and then diffuses into the nasal cavities. This study examined whether or not nasal NO concentration is affected by paranasal sinus inflammatory diseases.

The influence of obstruction (nasal polyposis) and/or inflammation (allergy or chronic sinusitis) of the paranasal sinuses on nasal NO concentration was evaluated in nasal allergic $(n=7$ patients) or nonallergic $(n=20)$ polyposis, nonallergic chronic sinusitis $(n=10)$ and Kartagener's syndrome $(n=6)$ and compared with control subjects $(n=42)$. A score of alteration of the paranasal sinus (number of altered and occluded sinuses) was determined by a computed tomography scan.

The nasal NO concentration in nasal nonallergic polyposis $(150 \pm 20$ parts per billion (ppb)) was significantly decreased compared with both controls $(223 \pm 6 \mathrm{ppb}$, $\mathbf{p}=\mathbf{0 . 0 1})$ and polyposis with allergy $(272 \pm 28 \mathrm{ppb}, \mathbf{p}<0.0001)$. In each group, the nasal NO concentration was inversely correlated with the extent of tomodensitometric alteration of the paranasal sinuses. In Kartagener's syndrome, the nasal NO concentration (14 $\pm 2 \mathrm{ppb})$ was drastically decreased compared with all other groups, despite the presence of open paranasal sinuses.

Thus, the nasal NO concentration in patients with nasal polyposis appeared to be dependent on both the allergic status and the degree of obstruction of the paranasal sinuses.

Eur Respir J 1999; 13: 307-312.
*Services d'Exploration Fonctionnelle Respiratoire, ${ }^{+}$de Pneumologie et d'Allergologie Adulte et Infantile, et $* * \mathrm{~d}^{\prime} \mathrm{ORL}$ CHU Rangueil et Purpan, Toulouse, France.

Correspondence: J-F. Arnal

Service d'Exploration Fonctionnelle Respiratoire

CHU Rangueil

31403 Toulouse Cedex

France

Fax: 33561322108

\section{Keywords: Allergy}

chronic sinusitis

Kartagener's syndrome

nasal polyposis

nitric oxide

Received: March 181998

Accepted after revision September 31998
The discovery that mammalian cells generate nitric oxide, a free radical gas previously considered merely as an atmospheric pollutant, is providing important information about many biological processes. NO is generated from arginine by a family of enzymes, the NO synthases (NOS), and acts as an autocrine and paracrine messenger [1, 2]. NO also plays a major role in nonspecific host defence as a result of its antiviral and antibacterial properties. Type II NOS, initially characterized in the rodent macrophage, has been shown to be expressed only after induction by pro-inflammatory cytokines or bacterial lipopolysaccharide [1]. This isoform can be expressed by most cells involved in inflammation and is also called inducible NOS [3].

Recently, LUNDBERG and coworkers [4-6] have clearly shown that most of the NO in the exhaled air of healthy subjects originates from the upper respiratory tract, with only a minor contribution from the lower airways. A type II NOS, mainly expressed in the epithelium of the paranasal sinuses, would account for most of this NO production [6]. Thus, NO could play a critical role in the physiology and pathology of the upper respiratory tract because, in addition to its role in immunity and host defence [3], NO stimulates ciliary motility [7]. Interestingly, LUNDBERG et al. [8] showed that patients with Kartagener's syndrome (referred to as an immobile cilia syndrome and characterized by situs inversus, sinusitis and bronchiectasis) had very low nasal NO concentrations. The present authors [9] and others [10] have recently shown that the nasal NO concentration in patients with allergic rhinitis is increased about two-fold.

In the present study, the effect of obstruction and/or inflammation of the paranasal sinuses on nasal NO concentration was examined. Nasal NO levels were determined in patients with nasal polyposis (allergic and nonallergic), chronic sinusitis or Kartagener's syndrome and compared with those of control subjects. The alteration to the paranasal sinus was established using computed tomography (CT) scans in the same patients, to evaluate the relationship between the number of altered and/or occluded sinuses and the nasal NO concentration.

\section{Subjects and methods}

The procedures employed in this study were reviewed and approved by the local Ethics Committee (Comité 
consultatif de protection des personnes). The study was performed in the following groups: nasal polyposis (27 patients), chronic sinusitis (10), Kartagener's syndrome (6) and control (42 nonsmoking subjects).

The diagnosis of patients with nasal polyposis was based on the endoscopic observation of nasal polyps. The diagnosis of patients with chronic sinusitis was based on the clinical history, endoscopic examination and CT scanning. Kartagener's syndrome was defined by the triad consisting of situs inversus, sinusitis and bronchectasis. The control group included 42 nonsmoking control subjects who had no personal or parental history of rhinitis and no personal symptoms of atopy (eczema, urticaria, etc.)

Each patient was asked about any history of allergic rhinitis and had skin tests to aeroallergens. Clinical symptoms of the upper airways were assessed the day of the NO measurement. The presence of symptoms (nasal obstruction, rhinorrhoea and sneezing) on the day of the NO measurement was noted and the intensity $(0,1,2$ or 3$)$ of each symptom was evaluated. Symptoms and treatments with oral, nasal or inhaled steroids are summarized in table 1 .

Skin-prick tests were performed in all patients with 14 different aeroallergens (house dust mite (Dermatophagoides pteronyssinus and farinae), cockroach, animal danders (dog and cat), grass pollen, artemisia pollen, pellitory, birch, ash, weeds (groups 1, 2 and 3) and alternaria). A positive control using $9 \%$ codeine phosphate and a negative control were carried out at the same time. The skin reaction was measured after $10-15 \mathrm{~min}$ and the test was considered positive if the induced induration was more than 4 $\mathrm{mm}$ greater than the negative control. Seven out of 27 patients with nasal polyposis had a history of allergic rhinitis and gave at least one positive skin test, whereas 20 out of 27 patients with nasal polyposis had no typical history of allergic rhinitis and gave a negative skin test. Skin reactions were negative in all patients with chronic sinusitis and in all control volunteers.
Each patient had a CT scan $(2 \mathrm{~mm}$ sections every 5 $\mathrm{mm}$ ) during the week before the NO measurement. The status of each sinus was scored as normal (0), abnormal but permeable (1) or occluded (2). The total score was calculated by summing the score of the four sinuses (maxillary, ethmoidal, sphenoidal and frontal) on each side (right and left).

\section{Measurement of nitric oxide}

A chemiluminescence NO analyser (Cosma, Igny, France) sampling with a constant flow of $0.7 \mathrm{~L} \cdot \mathrm{min}^{-1}$ was used. The sensitivity of the analyser was 1 part per billion (ppb). The probe was connected to a polystyrene nasal olive and gently introduced into the vestibulum of one nostril. Patients were asked to breathe through the mouth, without speaking or swallowing (these manoeuvres were found to increase nasal NO concentration by closure of the soft palate). The contralateral nostril was left open. Plateau levels of NO were registered on a chart recorder and were attained in $<2 \mathrm{~min}$. The atmospheric NO in the room was always $<5 \mathrm{ppb}$. The measurement was performed in the right nostril, then in the left nostril. The reproducibility of the measure had previously been assessed by repeating it after 15 min on the same day and by repeating it every morning from Monday-Friday (day-today) in 10 control subjects. The 15-min and day-to-day coefficients of variation were 7 and $10 \%$, respectively [9]. The 15-min and 24-h reproducibilities of the NO measurement were also assessed in seven patients with nasal polyposis: the coefficients of variation were 9 and $13 \%$, respectively.

The concentrations of orally exhaled NO were also evaluated. Subjects were allowed to sit and breathe normally for $10 \mathrm{~min}$ before sample collection. Inspiration and expiration through the nose was prevented by a nose clip. NO-free air was inhaled directly from a reservoir (Tedlar

Table 1. - Characteristics of control subjects and patients with nasal nonallergic and allergic polyposis, chronic sinusitis or Kartagener's syndrome

\begin{tabular}{|c|c|c|c|c|c|}
\hline & Control & $\begin{array}{l}\text { Nasal polyposis } \\
\text { without allergy }\end{array}$ & $\begin{array}{l}\text { Nasal polyposis } \\
\text { with allergy }\end{array}$ & $\begin{array}{l}\text { Chronic } \\
\text { sinusitis }\end{array}$ & $\begin{array}{c}\text { Kartagener's } \\
\text { syndrome }\end{array}$ \\
\hline $\mathrm{n}$ & 42 & 20 & 7 & 10 & 6 \\
\hline Age yrs & $42 \pm 3$ & $48 \pm 3$ & $42 \pm 2$ & $47 \pm 4$ & $30 \pm 4$ \\
\hline Sex M/F & $22 / 18$ & $13 / 7$ & $5 / 2$ & $7 / 3$ & $3 / 3$ \\
\hline \multicolumn{6}{|l|}{ Symptom score (0-3 each) } \\
\hline Nasal obstruction & 0 & $2.5 \pm 0.2$ & $2.2 \pm 0.2$ & $2.0 \pm 0.3$ & $2.1 \pm 0.2$ \\
\hline Rhinorrhoea & 0 & $1.1 \pm 0.2$ & $1.2 \pm 0.3$ & $1.0 \pm 0.4$ & $1.1 \pm 0.2$ \\
\hline Sneezing & 0 & $0.9 \pm 0.2$ & $1.2 \pm 0.2$ & $1.0 \pm 0.3$ & $0.7 \pm 0.3$ \\
\hline Smoking & 0 & 3 & 3 & 2 & 1 \\
\hline Asthma & 0 & 2 & 5 & 1 & 0 \\
\hline \multicolumn{6}{|l|}{ Treatment } \\
\hline Nasal inhaled corticoids & 0 & 0 & 0 & 0 & 1 \\
\hline Buccal inhaled corticoids & 0 & 0 & 0 & 0 & 0 \\
\hline Oral corticoids & 0 & 11 & 1 & 7 & 1 \\
\hline \multicolumn{6}{|l|}{ Nasal NO concentration ppb } \\
\hline Right & $\begin{array}{l}219 \pm 9 \\
(125-305)\end{array}$ & $\begin{array}{l}148 \pm 18 \\
(20-300)\end{array}$ & $\begin{array}{c}278 \pm 43 \\
(130-240)\end{array}$ & $\begin{array}{c}202 \pm 29 \\
(100-340)\end{array}$ & $\begin{array}{l}15 \pm 2 \\
(10-25)\end{array}$ \\
\hline Left & $\begin{array}{c}226 \pm 10 \\
(135-312)\end{array}$ & $\begin{array}{l}152 \pm 25 \\
(20-310)\end{array}$ & $\begin{array}{l}267 \pm 40 \\
(70-430)\end{array}$ & $\begin{array}{l}177 \pm 26 \\
(70-300)\end{array}$ & $\begin{array}{l}14 \pm 2 \\
(8-25)\end{array}$ \\
\hline Orally exhaled NO concentration ppb & $8 \pm 1$ & $6 \pm 1$ & $12 \pm 2$ & $7 \pm 1$ & $7 \pm 1$ \\
\hline
\end{tabular}

Data are shown as mean \pm SEM with ranges in parenthesis. M: male; F: female; ppb: parts per billion. 
bag; Hoffmann-Plastiques, Saint-Etienne, France) containing medical air (NO concentration $<1 \mathrm{ppb}$ ). Subjects exhaled through a mouthpiece and the orally exhaled air was taken into tubes via a nonrebreathing valve and collected in a 10-L Tedlar bag. The patients were asked to breathe normally through the mouth in order to fill the $10-\mathrm{L}$ bag within $1 \mathrm{~min}$ (expiratory output of $\sim 8-10 \mathrm{~L} \cdot \mathrm{min}^{-1}$ ). The NO concentration in the bag containing the orally exhaled air was measured with the chemiluminescence NO analyser immediately after collection. Preliminary experiments showed that NO remained stable in a Tedlar bag for at least $15 \mathrm{~min}$.

\section{Statistical analysis}

The data are expressed as mean \pm SEM. Comparisons of data between different groups were made by analysis of variance (ANOVA) and a Scheffé's post hoc test used when differences were indicated. Linear regression curves and correlation coefficients were obtained by the leastsquares method. Values of $\mathrm{p}<0.05$ for comparisons were considered significant.

\section{Results}

In normal subjects (control group), the NO concentration was $219 \pm 9 \mathrm{ppb}$ in the right nostril and $226 \pm 10 \mathrm{ppb}$ in the left nostril and there was a close correlation between the NO concentrations in both nostrils $(r=0.83, p<0.0001)$. An average value was calculated from the right and left values. As shown in figure 1 , these values were not affected by age ( $\mathrm{r}=0.10, \mathrm{p}=0.50$; NS).

The characteristics of the patients in the different groups are described in tables 1 and 2 . The nasal NO concentration (mean of the right and left concentration \pm SEM) in patients with chronic nonallergic sinusitis (172 \pm 30 $\mathrm{ppb})$ did not differ significantly from the controls $(223 \pm 6$ $\mathrm{ppb}$ ), based on ANOVA and the Scheffé test (fig. 2).

The nasal NO concentration in nasal nonallergic polyposis (146 $\pm 13 \mathrm{ppb}, 20$ patients) was significantly decreased compared with that of the controls $(\mathrm{p}=0.01)$. The

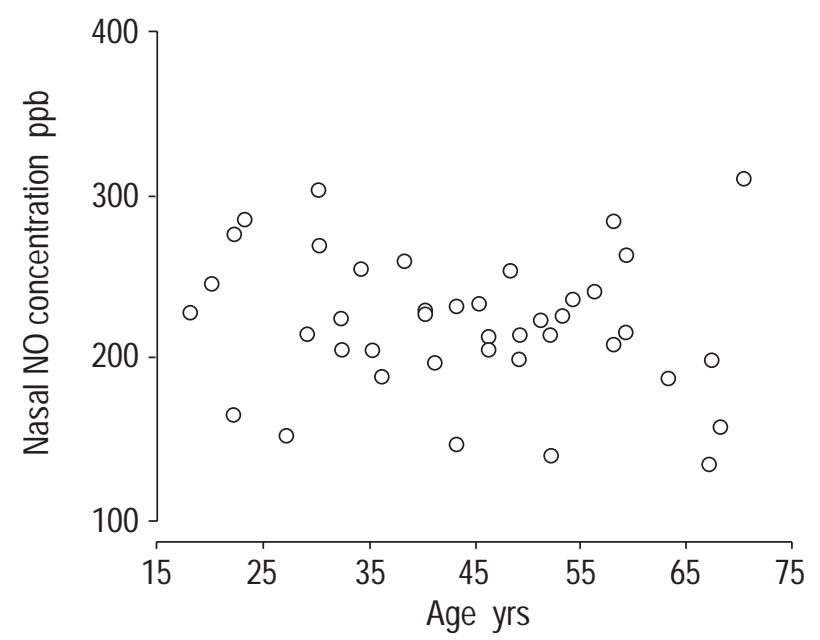

Fig. 1. - Absence of influence of age (yrs) on mean nitric oxide concentration (parts per billion (ppb)) in control subjects $(\mathrm{r}=0.10, \mathrm{NS})$. nasal NO concentration was not significantly different in patients given oral corticoids $(157 \pm 22 \mathrm{ppb}, \mathrm{n}=11)$ compared with patients without oral corticoids $(135 \pm 24 \mathrm{ppb}$, $\mathrm{n}=9$ ). In contrast, the nasal NO concentration in polyposis with allergy $(272 \pm 28 \mathrm{ppb})$ tended to be increased compared with the controls and was significantly increased in relation to nonallergic polyposis $(\mathrm{p}<0.0001)$. As corticosteroids have been reported to influence NO levels, the nasal NO concentration was compared in subgroups which did not receive corticosteroid treatment: nonallergic polyposis $(n=9)$ and allergic polyposis $(n=6)$. The nasal NO concentration in untreated allergic polyposis $(270 \pm 30 \mathrm{ppb})$ was significantly higher than in untreated nonallergic polyposis $(135 \pm 24 \mathrm{ppb})(\mathrm{p}<0.001)$.

In nonallergic patients with polyposis, the NO concentration was inversely correlated with the extent of tomodensitometric alterations of the paranasal sinuses induced by the polyps $(r=-0.41, p=0.01)$ (fig. 3 ) as well as with the number of occluded paranasal sinuses $(\mathrm{r}=-0.46$, $\mathrm{p}=0.003$ ) (fig. 4). Although the correlation was statistically significant, a broad dispersion of the nasal NO concentrations was observed for a similar degree of obstruction of the paranasal sinuses. In two patients, the occlusion of only one sinus (maxillary in one patient and sphenoidal in the other patient) was associated with a drop (compared with control patients) in nasal NO concentration (80 and $40 \mathrm{ppb}$, respectively), despite the presence of three other open homolateral sinuses. Conversely, occlusion of the four homolateral sinuses (maxillary, ethmoidal, sphenoidal and frontal) was associated with a homolateral nasal NO concentration of $100 \mathrm{ppb}$ in one other patient.

In patients with allergic polyposis, the NO concentration was inversely correlated with the extent of CT scan alterations of the paranasal sinuses $(r=-0.69, p<0.0001)$ (fig. 3 ) as well as with the number of occluded paranasal sinuses $(\mathrm{r}=-0.66, \mathrm{p}=0.0001)$ (fig. 4). The slopes of the regression line of nasal NO as a function of paranasal sinus alteration or occlusion did not differ between allergic and nonallergic polyposis, whereas the intercept of these regression lines with the y-axis differed significantly. This indicates that, for a similar degree of sinus alteration, the nasal NO was higher in allergic than in nonallergic patients. For instance, in two allergic patients, the occlusion of the four homolateral sinuses (maxillary, ethmoidal, sphenoidal and frontal) was associated with homolateral nasal NO concentrations of 240 and $130 \mathrm{ppb}$.

In Kartagener's syndrome, the nasal NO concentration $(13 \pm 1 \mathrm{ppb})$ was dramatically decreased compared with all other groups, despite the presence of open paranasal sinuses apparent on the CT scan. The nasal NO concentration (mean \pm SEM) in patients with nonallergic chronic sinusitis $(172 \pm 30 \mathrm{ppb})$ did not differ significantly from that of controls (228 $\pm 6 \mathrm{ppb})$.

NO concentration was also measured in orally exhaled air (table 1). The NO concentration did not differ between groups, except in patients with nasal polyposis and allergy, who showed increased levels $(\mathrm{p}<0.05$ versus control).

\section{Discussion}

The three major findings of the present study were as follows. 1) The nasal NO concentration in nonallergic 
Table 2. - Tomodensitometric abnormalities of the patients with nasal nonallergic and allergic polyposis, chronic sinusitis or Kartagener's syndrome

\begin{tabular}{|c|c|c|c|c|}
\hline & $\begin{array}{l}\text { Nasal polyposis } \\
\text { without allergy }\end{array}$ & $\begin{array}{l}\text { Nasal polyposis } \\
\text { with allergy }\end{array}$ & Chronic sinusitis & $\begin{array}{c}\text { Kartagener's } \\
\text { syndrome }\end{array}$ \\
\hline $\mathrm{n}$ & 20 & 7 & 10 & 6 \\
\hline \multicolumn{5}{|l|}{ Right } \\
\hline Abnormal sinuses & $3.2 \pm 0.2$ & $2.4 \pm 0.5$ & $1.5 \pm 0.5$ & $3.3 \pm 0.3$ \\
\hline Occluded sinuses & $1.4 \pm 0.3$ & $1.4 \pm 0.5$ & $0.8 \pm 0.3$ & $0.8 \pm 0.3$ \\
\hline \multicolumn{5}{|l|}{ Left } \\
\hline Abnormal sinuses & $3.2 \pm 0.2$ & $2.5 \pm 0.5$ & $1.3 \pm 0.4$ & $3.1 \pm 0.3$ \\
\hline Occluded sinuses & $1.5 \pm 0.4$ & $1.7 \pm 0.6$ & $0.8 \pm 0.2$ & $0.9 \pm 0.3$ \\
\hline
\end{tabular}

Data are shown as mean \pm SEM.

patients with nasal polyposis was significantly decreased compared with that of the controls and a correlation was found between the degree of obstruction of the paranasal sinuses and the nasal NO concentrations. 2) For a similar degree of sinus alteration, the nasal NO concentration was higher in allergic than in nonallergic patients with nasal polyposis. 3) Despite the anatomical persistence of paranasal sinuses, the nasal NO concentration collapsed completely in patients with Kartagener's syndrome.

Air sampled from nostrils and nasal cavities is supposed to reflect NO production in the upper airways (mainly paranasal sinuses but also nasal mucosa) and air exhaled during orally exhaled expiration that of NO production in the lower airways. However, owing to communication between the upper and lower airways through the soft palate, NO production in the lower airways may influence the nasal NO concentration. Several lines of evidence demonstrate that nasal NO is produced mainly in the upper airways. Subjects with a permanent tracheostomy exhale only very low NO levels $(2 \pm 0 \mathrm{ppb})$ when breathing through the tracheostomy, while the same individuals show considerably higher exhaled NO levels when breathing through the mouth $(14 \pm 2 \mathrm{ppb})[8]$. At least $50 \%$ of the exhaled NO has been shown to come from the nose during mouth breathing with an open posterior nasopharynx [1114]. Thus, when evaluating NO excretion in the lower airways during an exhalation, appropriate measures such as exhaling against a resistance to close the soft palate must

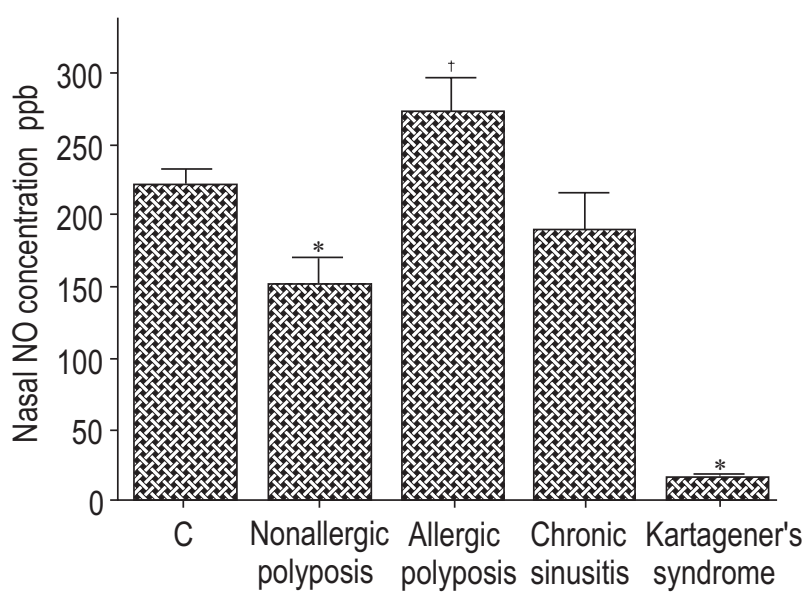

Fig. 2. - Nasal nitric oxide concentration (parts per billion (ppb)) in control subjects $(\mathrm{C})$ and in patients with nasal nonallergic and allergic polyposis, chronic sinusitis and Kartagener's syndrome. *: $\mathrm{p}<0.05$ versus control; ${ }^{\dagger}$ : $\mathrm{p}<0.05$ allergic versus nonallergic polyposis. be taken to separate the nasal passages from the rest of the respiratory tract [15]. The NO concentration in the lower airways is, thus, 20-fold lower than that in the upper airways in normal subjects [15]; however, the NO concentration in the lower airways of asthmatic patients has been shown to be increased $[4,10,13]$. In order to evaluate precisely the degree of contamination of nasal NO concentration by NO contained in air aspired from the lower airways, the concentrations of orally exhaled NO were assessed in patients breathing with a noseclip. Orally exhaled air is indeed representative of the air aspired in the oropharynx when sampling nasal air. The NO concentrations did not differ between groups, except in patients with nasal polyposis and allergy, who had increased levels. The presence of asthma in five out of seven of these patients could account for the enhanced NO levels in exhaled air, as previously reported $[4,10,13]$. Thus, in all groups, contamination of nasal air by NO present in the lower airways represented no more than $5 \%$ of the nasal NO concentration and could not account for the large differences in nasal NO concentration between allergic and nonallergic patients. Thus, even if the aspiration of nasal air from a single nostril samples an admixture of lower airways NO and diffused NO from the upper airways (both nasal and paranasal sinuses), it mainly reflects that produced by the upper airways.



Fig. 3. - Correlation between the number of abnormal sinuses and the homolateral nasal nitric oxide concentration (parts per billion (ppb)) in

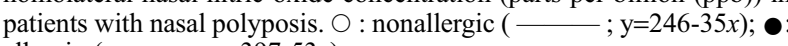
allergic $(----; y=397-53 x)$. 




Fig. 4. - Correlation between the number of occluded sinuses and the homolateral nasal nitric oxide concentration (parts per billion (ppb)) in patients with nasal polyposis $(\mathrm{r}=0.38, \mathrm{p}=0.02)$. $\bigcirc$ : nonallergic $(\longrightarrow$; $\mathrm{y}=186-31 x)$; $:$ allergic $(---; \mathrm{y}=341-45 x)$.

NO is generated from arginine by a family of NOS enzymes, and three distinct isoforms of human NOS have been characterized to date $[1,2]$. Two of these isoforms, endothelial and neuronal NOS, are constitutively expressed and changes in their activity regulate vascular tone, platelet activation and neurotransmission. A third isoform has been found to be expressed upon stimulation with proinflammatory cytokines by most of the cell types within the organism and has been called inducible NOS [3]. LUNDBERG et al. [6] clearly showed that epithelial cells lining the sinuses of subjects without clinical sinus inflammation expressed an NOS characterized as the inducible isoform by in situ hybridization and immunohistochemical techniques. These authors demonstrated dir-ectly that this type II NOS was mainly responsible for the very high sinus and high nasal NO concentrations produced in the normal upper airways.

Even though the nucleotide sequences of the paranasal sinuses NOS and the classical type II NOS would appear identical, the regulation of their expression and/or activity could be different. However, LUNDBERG et al.[16] also demonstrated that the nasal NO concentration of patients with normal upper airways was not influenced by high systemic doses of corticosteroids. On the other hand, glucocorticoids are well-known inhibitors of the classical inducible type II NOS expression [17] and the topically applied steroids are associated with reduced values of nasal NO compared with untreated allergic rhinitis [10]. The ability of topically applied steroids to decrease both nasal symptoms and nasal NO levels suggests that the elevation of NO in allergic rhinitis is unlikely to be derived from paranasal sinuses, which should not be affected by steroids applied in nasal sprays [10]. Altogether, these different studies and the present one support the idea that the type II NOS expressed in the paranasal sinus represents a permanent, normal, first line of host defence, whereas the classical, inducible type II NOS is only expressed in response to inflammatory stimuli (e.g. the nasal mucosa in allergic rhinitis).

What is the main source of nasal NO in diseased paranasal sinuses? A significant correlation $(r=-0.41, p=0.01)$ was found between the degree of obstruction of the paranasal sinuses by polyps and nasal NO concentration, suggesting that the sinuses contribute to nasal NO. However, figure 2 shows a large dispersion of the nasal NO concentration for a similar degree of obstruction of the paranasal sinuses, suggesting that sites of production other than the sinuses also contribute to the nasal NO. Several recent publications may help in understanding these results. Firstly, the normal, noninflamed nasal mucosa can itself express NOS [18]. Secondly, it has recently been shown that the epithelium of the polyps, which originate from the sinus, express the inducible type III NOS [19]. Consequently, the polyps can also generate NO and may themselves contribute to NO production. Thirdly, nasal steroids reduce nasal NO in allergic rhinitis [10], suggesting that inflammatory nasal mucosa can express a classic inducible and steroid-repressible NOS II. Indeed, for a similar degree of paranasal sinus alteration, allergic patients demonstrated higher levels of nasal NO than nonallergic patients. Thus, although the obstruction of the paranasal sinuses by the polyps statistically decreases the nasal NO concentration, other factors, such as allergy, strongly influence nasal NO concentration.

The nasal NO concentration was very low in all patients with Kartagener's syndrome, as reported previously [8]. In addition, the present study demonstrates that this occurred despite open paranasal sinuses in all of the patients with Kartagener's syndrome. This contrasts with the absence of a significant decrease $(23 \%)$ in $\mathrm{NO}$ concentration in patients with chronic sinusitis. However, as the degree of paranasal sinus alteration was less in chronic sinusitis than in the other three groups, it cannot definitively be concluded that chronic sinusitis does not alter nasal NO levels. Furthermore, a significant decrease in nasal NO (59\%) has previously been reported in another group of patients with chronic sinusitis [20]. In this latter study, extensive alterations to the paranasal sinuses could be responsible for the significant decrease in nasal NO levels. In any case, the decrease in nasal NO levels in chronic sinusitis was less pronounced than the dramatic drop found in Kartagener's syndrome and nasal NO concentration could thus represent a fourth criterion for the diagnosis of Kartagener's syndrome. These observations also suggest that a specific abnormality of NO synthase activity characterizes Kartagener's syndrome, and this could represent a unique example of an NOS defect in humans [3]. This observation should stimulate future work in this field.

The sharp decrease in nitric oxide production in patients with Kartagener's syndrome or in certain patients with polyps could have important pathophysiological consequences. Nitric oxide plays an important role in immunity and host defence $[3,21]$ and stimulates ciliary motility [7]. RUNNER and coworkers [22, 23] have demonstrated the physiological importance of nitric oxide on the mucociliary activity in the human nose and correlated decreased nasal nitric oxide to impaired mucociliary function in the upper airways. The drop in nasal nitric oxide concentration in certain patients could involve a decreased production and/or an increased breakdown of nitric oxide by inflammation-derived reactive oxygen species [24]. Indeed, phagocytic cells (polymorphonuclear and monocyte-macrophage cells) generate high levels of superoxide anion through the activation of nicotinamide adenine dinucleotide phosphate (reduced) oxidase [25]. As superoxide 
anion is recognized to be one of the major inactivators of nitric oxide, it can be speculated that inflammation could contribute to decrease nitric oxide levels. Conversely, the increased release of nitric oxide in allergic patients could increase airway blood flow and cause hyperaemia, induce airway oedema by plasma exudation and modulate sensory nerve endings $[26,27]$. Consequently, increased nitric oxide could not only contribute to nasal congestion, rhinorrhoea and sneezing, but also worsen retention of mucus and infection by decreasing sinus permeability. In any case, further work is required to clarify the precise role of nitric oxide in paranasal sinus pathology.

\section{References}

1. Moncada S, Higgs A. The L-arginine-nitric oxide pathway. N Engl J Med 1993; 329: 2002-2012.

2. Förstermann U, Closs EI, Pollock JS, et al. Nitric oxide synthase isozymes. Characterisation, purification, molecular cloning, and functions. Hypertension 1994; 23: $1121-1131$.

3. Nathan C. Inducible nitric oxide synthase: what difference does it make? J Clin Invest 1997; 100: $2417-$ 2423.

4. Alving K, Weitzberg E, Lundberg J. Increased amount of nitric oxide in exhaled air of asthmatics. Eur Respir $J$ 1993; 6: 1368-1370.

5. Lundberg J, Rinder J, Weitzberg E, Lundberg J, Alving K. Nasally exhaled nitric oxide originates mainly in the paranasal sinuses. Acta Physiol Scand 1994; 152: 431432.

6. Lundberg J, Farkas-Szallasi T, Weitzberg E, et al. High nitric oxide production in human paranasal sinuses. Nature Med 1995; 1: 370-373.

7. Jain B, Rubinstein I, Robbins R, Leise K, Sisson J. Modulation of airway epithelial cell ciliary beat frequency by nitric oxide. Biochem Biophys Res Commun 1993; 191: 83-88.

8. Lundberg J, Weitzberg E, Nordvall S, Kuylenstierna R, Lundberg J, Alving K. Primarily nasal origin of exhaled nitric oxide and absence in Kartagener's syndrome. Eur Respir J 1994; 7: 1501-1504.

9. Arnal JF, Didier A, Rami J, et al. Nasal nitric oxide is increased in allergic rhinitis. Clin Exp Allergy 1997; 27: 358-362.

10. Kharitonov S, Rajakulasingam K, O'Connor B, Durham $\mathrm{S}$, Barnes P. Nasal nitric oxide is increased in patients with asthma and allergic rhinitis and may be modulated by nasal glucocorticoids. J Allergy Clin Immunol 1997; 99: $58-64$.

11. Schedin U, Frostell C, Persson MG, Jakobsson J, Andersson G, Gustafsson LE. Contribution from upper and lower airways to exhaled endogenous nitric oxide in humans. Acta Anaesthesiol Scand 1995; 39: 327-332.

12. Phillips C, Giraud G, Holden W. Exhaled nitric oxide during exercise: site of release and modulation by ventilation and blood flow. J Appl Physiol 1996; 80: 18651871.

13. Lundberg J, Weitzberg E, Lundberg J, Alving K. Nitric oxide in exhaled air. Eur Respir J 1996; 9: 2671-2680.

14. Arnal J, Galinier M, Mazerolles M, et al. Nasal nitric oxide concentration is decreased in heart failure patients receiving nitrates. Fundam Clin Pharmacol 1998; 12: 95100.

15. Kharitonov S, Alving K, Barnes P. Exhaled and nasal nitric oxide measurements: recommendations. Eur Respir $J$ 1997; 10: 1683-1693.

16. Lundberg J, Weitzberg E, Rinder J, et al. Calciumindependent and steroid-resistant nitric oxide synthase activity in human paranasal sinus mucosa. Eur Respir $J$ 1996; 9: 1344-1347.

17. Nathan $\mathrm{C}, \mathrm{Xie} \mathrm{QW}$. Regulation of biosynthesis of nitric oxide. J Biol Chem 1994; 269: 13725-13728.

18. Furukawa K, Harrison D, Saleh D, Shennib H, Chagnon F, Giaid A. Expression of nitric oxide synthase in the human nasal mucosa. Am J Respir Crit Care Med 1996; 153: 847-850.

19. Ramis I, Lorente J, Rosello-Catafau J, Quesada P, Gelpi E, Bulbena O. Differential activity of nitric oxide synthase in human nasal mucosa and polyps. Eur Respir $J$ 1996; 9: 202-206.

20. Lindberg S, Cervin A, Runner T. Nitric oxide production in the upper airways is decreased in chronic sinusitis. Acta Otolaryngol 1997; 117: 113-117.

21. Mancinelli R, McKay C. Effects of nitric oxide and nitrogen dioxide on bacterial growth. Appl Environ Microbiol 1983; 46: 198-202.

22. Lindberg S, Cervin A, Runner T. Low levels of nasal nitric oxide correlate to impaired mucociliary function in the upper airways. Acta Otolaryngol 1997; 117: 728-734.

23. Runner T, Lindberg S. Effects of nitric oxide on blood flow and mucociliary activity in the human nose. Ann Otol Rhinol Laryngol 1998; 107: 40-46.

24. Rubbo H, Darley-Usmar V, Freeman B. Nitric oxide regulation of tissue free radical injury. Chem Res Toxicol 1996; 9: 809-820.

25. Someya A, Nishijima K, Nunoi H, Irie S, Nagaoka I. Study of the superoxide-producing enzyme of eosinophils and neutrophils - comparison of the NADPH oxidase components. Arch Biochem Biophys 1997; 345: 207-213.

26. Barnes P, Belvisi M. Nitric oxide and lung disease. Thorax 1993; 48: 1034-1043.

27. Nijkamp F, Folkerts G. Nitric oxide: initiator and modulator. Clin Exp Allergy 1997; 27: 347-350. 